\title{
ANALISA HUBUNGAN BRAND STRATEGY YANG DILAKUKAN GOOTA JAPANESE CHARCOAL GRILL AND CAFE DAN BRAND EQUITY YANG SUDAH DITERIMA KONSUMEN
}

\author{
Fera Kusno \\ Supervisor Sushi-Tei Japanese Restaurant \\ e-mail: fera_kusno@yahoo.com \\ Amanda Radityani \\ Alumnus Program Manajemen Perhotelan Fakultas Ekonomi Universitas Kristen Petra \\ e-mail: skolastika_amanda@yahoo.com \\ Monika Kristanti \\ Dosen Program Manajemen Perhotelan, Fakultas Ekonomi Universitas Kristen Petra \\ e-mail: mkrist2001@yahoo.com
}

\begin{abstract}
Abstrak: Goota Japanese charcoal grill and café sebagai restoran baru di PTC-Supermal Pakuwon Indah melakukan brand strategy untuk mengenalkan brandnya, yang nantinya dapat menciptakan brand equity di benak konsumen. Untuk mengetahui brand strategy yang dilakukan Goota, dilakukan wawancara terhadap manager Goota, sedangkan untuk mengetahui brand equity yang sudah diterima konsumen, disebarkan kuisioner kepada para konsumen Goota. Didapatkan hasil bahwa hubungan kausal antara brand strategy (brand positioning, brand identity, brand personality, dan brand communication) dan brand equity adalah positif.
\end{abstract}

Kata kunci: brand strategy, brand equity, brand positioning, brand identity, brand personality, brand communication

\begin{abstract}
Goota Japanese charcoal grill and café as a new restaurant at PTC-Supermal Pakuwon Indah has done some brand strategies to acquaint its new brand that will create brand equity in the customers' mind. In order to know the brand strategy, the Goota's manager is interviewed, and for knowing the brand equity, customers are chosen to fill in the questionnaire. The result shows there is positive causal relationship between brand strategy (brand positioning, brand identity, brand personality, and brand communication) and brand equity.
\end{abstract}

Keywords: brand strategy, brand equity, brand positioning, brand identity, brand personality, brand communication

Seiring dengan perkembangan jaman, bisnis restoran di Surabaya telah menunjukkan pertumbuhan yang sangat pesat terutama di Surabaya bagian Barat. Hal ini dapat dilihat dari banyaknya restoran yang ada baik di dalam pusat perbelanjaan maupun di luar pusat perbelanjaan, seperti di PTC (Pakuwon Trade Center)-Supermal Pakuwon Indah. Goota adalah salah satu restoran Jepang yang baru dibuka tanggal 18 Juni 2006 di PTC, dimana konsep yang ditawarkan yaitu Japanese charcoal grill and café, yang menawarkan makanan khas Jepang yang dipadu dengan citarasa Korea.

Sebagai restoran baru yang tentunya mempunyai banyak pesaing, Goota harus dapat muncul dan berusaha agar dikenal bahkan unggul di pasaran, dan salah satu strategi adalah pemberian merek atau nama yang digunakan untuk membedakan perusahaan satu dengan yang lainnya (Kotler, 2002). Brand yang kuat serta mempunyai value akan dapat menciptakan kekuatan merek (brand equity) yang kemudian akan dapat menjadi keunggulan dari brand tersebut bila dibandingkan dengan brand lainnya juga sebagai nilai lebih yang menjadikan brand tersebut dinilai berbeda oleh konsumen ketika konsumen melakukan keputusan pembelian (Boone dan Kurtz, 2005).

Untuk dapat memperkenalkan brand Goota kepada konsumen, Goota melakukan brand strategy, dan salah satu brand strategy yang dilakukan adalah mengkomunikasikan brand itu kepada konsumen (Schultz dan Barnes, 1999). Cara lain yang dapat dilakukan adalah brand positioning, brand identity, brand personality, brand extension, rebranding, dan brand repositioning (Gelder, 2005). 
Berdasarkan wawancara personal dengan manager Goota, beliau menyatakan bahwa Goota memiliki spesialisasi makanan grill. Pemilihan spesialisasi ini mengandung pengertian bahwa penyajiannya simple dan praktis sesuai dengan target market Goota yaitu anak muda menengah ke atas. Selain itu konsep café yang diambil, membuat Goota merancang interiornya menjadi tempat yang nyaman tidak hanya untuk makan tetapi juga untuk berkumpul dan menghabiskan waktu bersama teman-teman.

Penulis memilih Goota karena melihat Goota sebagai industri makanan baru yang berani bersaing dengan restoran lainnya. Selain itu lokasi yang dipilih Goota merupakan lokasi yang dikenal cukup sepi pada hari biasa (weekdays) yaitu di Citywalk Supermal Pakuwon Indah (observasi penulis, 27 Juli 2006). Hal ini diperkuat dari data jumlah pengunjung pada bulan Juli dan Agustus 2006, dapat dilihat adanya perbedaan yang cukup signifikan antara weekdays dengan rata-rata pengunjung sebanyak 98 pengunjung dan weekends dengan rata-rata pengunjung sebanyak 215 pengunjung.

Berdasarkan fenomena di atas, penulis tertarik untuk meneliti brand strategy yang sudah dan akan dilakukan Goota mengingat Goota merupakan industri makanan baru yang harus memperkenalkan brand serta produknya dari awal kepada konsumen. Selain itu juga untuk mengetahui bagaimana tanggapan konsumen terhadap brand strategy yang sudah dilakukan Goota dan bagaimana per tingkatan brand equity yang sudah diterima oleh konsumen serta hubungan kausal yang terjadi antara brand strategy dan brand equity.

\section{TEORI PENUNJANG}

\section{Brand}

Menurut AMA (American Marketing Association), merek adalah nama, istilah, tanda, simbol, rancangan atau kombinasi dari hal-hal tersebut, yang dimaksudkan untuk mengidentifikasi barang atau jasa dari seorang atau sekelompok penjual dan untuk membedakannya dari produk pesaing (Kotler, 2002, p. 460). Menurut Giribaldi (2003), merek adalah kombinasi dari atribut-atribut, dikomunikasikan melalui nama atau simbol, yang dapat mempengaruhi proses pemilihan suatu produk atau layanan di benak konsumen (Soehadi, 2005, p. 2). Pendapat lain oleh Schultz (2004), "So, that's what we mean by a brand: something that is identifiable by the buyer and the seller and creates values for both" (p. 14), yang artinya merek adalah sesuatu yang dapat diidentifikasi oleh pembeli dan penjual sehingga menciptakan nilai bagi keduanya. Sedangkan Susanto dan Wijanarko (2004), merek adalah nama atau simbol yang diasosiasikan dengan produk atau jasa dan menimbulkan arti psikologis atau asosiasi (p. 5).

Jadi brand adalah identifikasi yang berupa nama atau simbol yang mempengaruhi proses pemilihan suatu produk atau jasa yang membedakannya dari produk pesaing serta mempunyai nilai bagi pembeli dan penjualnya.

\section{Brand Strategy}

Menurut Schultz dan Barnes (1999), brand strategy yang juga berarti manajemen merek dapat diartikan sebagai kegiatan yang mengatur semua elemen-elemen yang bertujuan untuk membentuk suatu brand. Sedangkan menurut Gelder (2005), "The brand strategy defines what the brand is supposed to achieve in terms of consumer attitudes and behaviour" (p. 29), yang artinya strategi merek mendefinisikan apa yang seharusnya dicapai suatu brand dalam kaitannya dengan sikap dan perilaku konsumen. Jadi brand strategy adalah suatu manajemen brand yang bertujuan untuk mengatur semua elemen brand dalam kaitannya dengan sikap dan perilaku konsumen.

Sedangkan menurut Gelder (2005), yang termasuk ke dalam brand strategy antara lain brand positioning, brand identity, dan brand personality. Sebagai tambahan, menurut Schultz dan Barnes (1999), yang juga termasuk ke dalam brand strategy yaitu brand communication.

\section{Brand Positioning}

Menurut Gelder (2005), "Brand positioning as a way of demonstrating a brand's advantage over and differentiation from its competition" (p. 31), yang artinya brand positioning adalah suatu cara untuk mendemonstrasikan keunggulan dari suatu merek dan perbedaannya dari kompetitor yang lain. Dalam definisi tradisional, positioning sering disebut sebagai strategi untuk memenangi dan menguasai benak pelanggan melalui produk yang ditawarkan. Namun menurut Kartajaya (2004), positioning didefinisikan sebagai the strategy to lead your customer credibly, yaitu upaya untuk mengarahkan pelanggan secara kredibel. Sedangkan menurut Susanto dan Wijanarko (2004), posisi merek adalah bagian dari identitas merek dan proposisi nilai yang secara aktif dikomunikasikan kepada target konsumen dan menunjukkan keunggulannya terhadap merek-merek pesaing (p. 143). Jadi brand positioning adalah cara perusahaan untuk menempatkan dirinya dimata target konsumen- 
nya dilihat dari keunggulan dan kelebihan yang dimiliki dibandingkan dengan brand pesaing.

\section{Brand Identity}

Menurut Gelder (2005), "Brand identity as a set of aspects that convey what a brand stands for: its background, its principles, its purpose and ambitions" (p. 35), yang artinya brand identity adalah suatu kumpulan dari aspek-aspek yang bertujuan untuk menyampaikan merek: latar belakang merek, prinsipprinsip merek, tujuan dan ambisi dari merek itu sendiri. Dan menurut Susanto dan Wijanarko (2004), brand identity dapat diartikan sebagai susunan katakata, kesan, dan sekumpulan bentuk dari sejumlah persepsi konsumen tentang merek (p. 87). Pendapat lain oleh Randall (2001), "Brand identity is what we transmit to the market place - it is what is under our control, provided that we understand the essence and expression of our brand" (p. 7), yang artinya brand identity adalah apa yang dikirimkan oleh perusahaan ke pasaran, dimana hal ini berada didalam kontrol perusahaan dan perusahaan menetapkan nilai dan ekspresi dari merek itu sendiri. Sedangkan menurut Crainer dan Dearlove (2003), "Brand identity is a concept that has recently been brought to the forefront of brands theory" (p. 120), yang artinya brand identity adalah suatu konsep yang menjadi dasar dari teori tentang merek. Dari definisi di atas, brand identity dapat diartikan sebagai persepsi tentang brand dari suatu perusahaan yang ingin disampaikan kepada konsumen sehingga dapat membentuk persepsi konsumen tentang brand itu sendiri.

\section{Brand Personality}

Pengertian brand personality menurut Gelder (2005), "Brand personality is developed to enhance the appeal of a brand to consumers" (p. 41), yang artinya brand personality adalah suatu cara yang bertujuan untuk menambah daya tarik merek dari luar dimata konsumen. Kemudian menurut Crainer dan Dearlove (2003), "Brand personality is a brand acquires a character through communication about the brand and experience of the brand and those persons identified with the brand" (p. 120), yaitu brand personality adalah merek yang didapat dari suatu karakter melalui komunikasi tentang merek dan pengalaman dari merek serta dari orang yang memperkenalkan merek. Sedangkan menurut Keller (1993), "Brand personality is the human characteristics or traits that can be attributed to a brand" (p. 444), yaitu brand personality adalah karakteristik manusia atau ciri-ciri yang dapat diatributkan kepada suatu merek. Jadi brand personality adalah suatu cara yang bertujuan untuk menambah daya tarik dari brand dengan memberi karakteristik pada brand tadi, yang bisa didapat melalui komunikasi, pengalaman serta dari orang yang memperkenalkan brand itu sendiri.

\section{Brand Communication}

Untuk dapat mengkomunikasikan brand kepada konsumen, perusahaan menggunakan komunikasi internal dan eksternal yaitu antara lain dengan sales promotion, events, public relations, direct marketing (pengiriman katalog, surat, telp, fax, atau email), corporate sponsorhips yaitu penawaran produk/jasa dengan bekerja sama dengan perusahaan lain sebagai sponsor, dan advertising yaitu cara-cara untuk memperkenalkan produk/jasa melalui segala macam iklan (Schultz dan Barnes, 1999, p. 45).

\section{Brand Equity}

Menurut Susanto dan Wijanarko (2004), dalam menghadapi persaingan yang ketat, merek yang kuat merupakan suatu pembeda yang jelas, bernilai, dan berkesinambungan, menjadi ujung tombak bagi daya saing perusahaan dan sangat membantu strategi pemasaran (p. 2). Keller (1993) menyatakan brand equity adalah keinginan seseorang untuk melanjutkan menggunakan suatu brand atau tidak. Pengukuran dari brand equity sangatlah berhubungan kuat dengan kesetiaan dan bagian pengukuran dari pengguna baru menjadi pengguna yang setia (p. 43).

Ada beberapa pengertian brand equity yang dikemukakan oleh beberapa ahli, yang pertama Susanto dan Wijanarko (2004), ekuitas merek adalah seperangkat aset dan liabilitas merek yang berkaitan dengan suatu merek, nama dan simbolnya, yang menambah atau mengurangi nilai yang diberikan oleh suatu barang atau jasa kepada perusahaan atau pelanggan (p. 127). Kemudian menurut East (1997), "Brand equity or brand strength is the control on purchase exerted by a brand, and, by virtue of this, the brand as an asset that can be exploited to produce revenue" (p. 29) yang berarti ekuitas merek atau kekuatan merek adalah kontrol dari pembelian dengan menggunakan merek, dan, kebaikan dari merek, merek sebagai aset yang dapat dimanfaatkan untuk menghasilkan pendapatan. Sedangkan menurut Kotler dan Armstrong (2004), "Brand equity is the positive differential effect that knowing the brand name has on customer response to the product or service" (p. 292), yang artinya ekuitas merek adalah efek diferensiasi yang positif yang dapat diketahui dari respon konsumen terhadap barang atau jasa. Jadi brand equity adalah kekuatan suatu brand yang dapat menambah atau mengurangi nilai dari brand itu 
sendiri yang dapat diketahui dari respon konsumen terhadap barang atau jasa yang dijual.

Susanto dan Wijanarko (2004) yang mengadaptasi teori Aaker, menyatakan bahwa brand equity dapat dikelompokkan ke dalam beberapa kategori:

a. Brand awareness, adalah kesanggupan seorang calon pembeli untuk mengenali atau mengingat kembali bahwa suatu merek merupakan bagian dari kategori merek tertentu. Sedangkan pendapat lain dari East (1997), "Brand awareness is the recognition and recall of $a$ brand and its differentiation from other brands in the field" ( $\mathrm{p}$. 29) yang berarti adalah pengakuan dan pengingatan dari sebuah merek dan pembedaan dari merek yang lain yang ada di lapangan. Jadi brand awareness adalah kemampuan konsumen untuk mengingat suatu brand dan yang menjadikannya berbeda bila dibandingkan dengan brand lainnya.

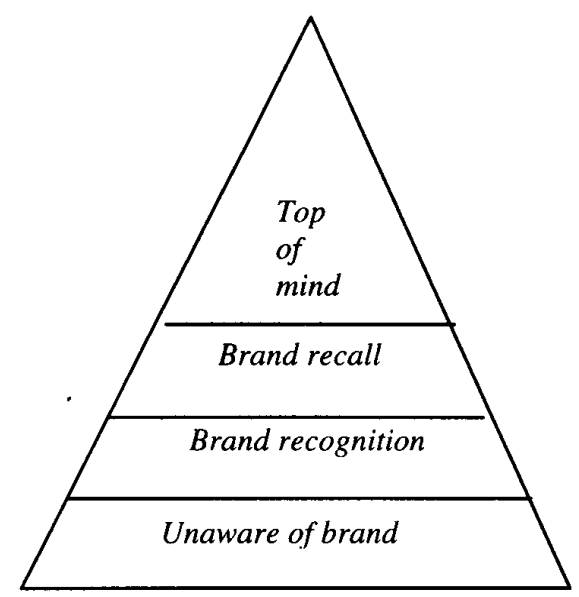

Sumber: Rangkuti, (2004, pp. 40-41)

\section{Gambar 1. Piramida Brand Awareness}

Ada 4 tingkatan brand awareness seperti yang dapat dilihat pada gambar 1. yaitu:

1. Unaware of brand (tidak menyadari merek); tingkat yang paling rendah dalam piramida kesadaran merek, dimana konsumen tidak menyadari adanya suatu merek.

2. Brand recognition (pengenalan merek); tingkat minimal dari kesadaran merek. Hal ini penting pada saat pembeli memilih suatu merek pada saat melakukan pembelian.

3. Brand recall (pengingatan kembali terhadap merek); didasarkan pada permintaan seseorang untuk menyebutkan merek tertentu dalam suatu kelas produk. Hal ini diistilahkan dengan pengingatan kembali tanpa bantuan, karena berbeda dari tugas pengenalan, responden tidak perlu dibantu untuk memunculkan merek tersebut.
4. Top of mind (puncak pikiran); apabila seseorang ditanya secara langsung tanpa diberi bantuan pengingatan dan orang tersebut dapat menyebutkan satu nama merek, maka merek yang paling banyak disebutkan pertama kali merupakan puncak pikiran. Dengan kata lain, merek tersebut merupakan merek utama dari berbagai merek yang ada di dalam benak konsumen.

b. Perceived quality, yaitu persepsi pelanggan terhadap keseluruhan kualitas atau keunggulan suatu produk atau jasa berkenaan dengan maksud yang diharapkan.

c. Brand association, adalah sesuatu yang berkaitan dengan ingatan mengenai sebuah produk. Asosiasi ini tidak hanya eksis, namun juga memiliki suatu tingkat kekuatan. Keterikatan pada suatu merek akan lebih kuat apabila dilandasi pada banyak pengalaman atau penampakan untuk mengkomunikasikannya.

d. Brand loyalty; merupakan ukuran kesetiaan seorang pelanggan pada sebuah merek.

\section{Kerangka Berpikir}

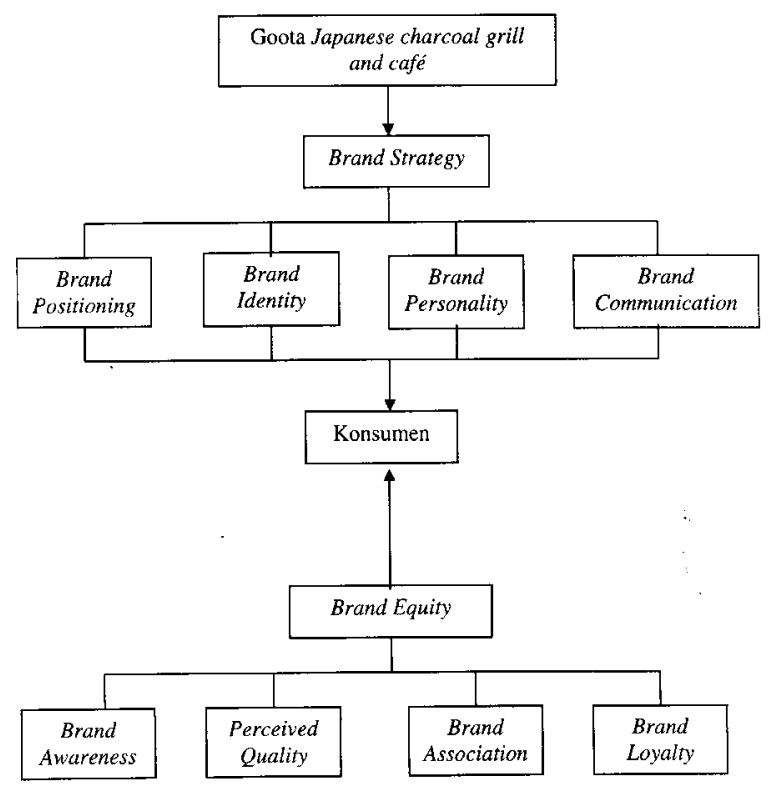

\section{METODOLOGI PENELITIAN}

\section{Jenis Penelitian, Teoritikal Sampling dan Penen- tuan Informan}

Jenis penelitian yang digunakan adalah penelitian deskriptif konklusif kualitatif dan kuantitatif. Populasi yang digunakan adalah para konsumen Goota. Sedangkan responden yang mengisi kuisioner dipilih dengan menggunakan convenience sampling, dimana 
peneliti dapat memilih siapapun responden yang ada sebagai partisipan (Cooper dan Schindler, 2006, p. 222). Dan sebagai informan dari Goota adalah Bapak Alvin Yap selaku manager Goota.

\section{Metode dan Prosedur Pengumpulan Data}

1. Wawancara, yaitu semi-structured interview dan wawancara terbuka terhadap manager Goota, Bapak Alvin Yap yang mengetahui segala hal yang berhubungan dengan Goota baik secara langsung maupun tidak langsung seperti marketing, advertising maupun hal lainnya.

2. Observasi, dilakukan secara langsung terhadap Goota yang meliputi pengamatan lokasi Goota, desain interior, atmosfer serta produk-produk yang ditawarkan Goota juga dari pengunjung yang datang apakah dapat mewakili target market yang ingin dicapai.

3. Kuisioner, disebarkan kepada konsumen Goota sebanyak 220 lembar dan 20 lembar dinyatakan tidak valid. Kuisioner terdiri dari 6 bagian pertanyaan, 4 bagian merupakan pertanyaan mengenai tingkatan brand equity dan 2 bagian lainnya merupakan pertanyaan mengenai brand strategy, yang mencakup brand positioning, brand identity, brand personality, dan brand communication. Pertanyaan untuk ketiga brand strategy yang pertama oleh penulis digabung menjadi 1 bagian dikarenakan kesamaan indikator yang digunakan.

4. Studi kepustakaan dan dokumen internal Goota.

\section{Definisi Operasional Variabel}

\section{A. Brand Equity}

1. Brand awareness, kemampuan konsumen untuk mengingat suatu brand dan yang menjadikannya berbeda bila dibandingkan dengan brand lainnya.

Tingkatan brand awareness (kesadaran merek) yaitu:

a. Unaware of brand; konsumen tidak menyadari akan adanya suatu merek.

Indikator empirik:

Responden tidak menyebutkan atau tidak mengetahui merek Goota Japanese charcoal grill and café.

b. Brand recognition (pengenalan merek); responden dibantu dengan pilihan merek.

Indikator empirik:

Responden mengenali merek Goota Japanese charcoal grill and café setelah diberikan pilihan bantuan. c. Brand recall (pengingatan kembali terhadap merek); merek yang disebutkan oleh responden tanpa dibantu dengan pilihan merek.

Indikator empirik:

Responden dapat menulis 3 nama restoran Jepang yang diingat yang ada di PTCSupermal Pakuwon Indah.

d. Top of mind (puncak pikiran); responden menyebut nama merek tersebut pertama kali.

Indikator empirik:

Responden menulis 1 restoran yang menjadi pilihan pertama yang diingat di PTCSupermal Pakuwon Indah.

2. Perceived quality; persepsi pelanggan terhadap keseluruhan kualitas atau keunggulan suatu produk atau jasa berkenaan dengan maksud yang diharapkan.

Indikator empirik:

a. Goota memberikan pilihan produk yang menarik, berkualitas, dan bervariasi.

b. Staf Goota menyajikan makanan dengan cepat ( \pm 15 menit).

c. Staf Goota berpenampilan rapi dan bersih.

d. Staf Goota memberikan kualitas pelayanan dan service yang memuaskan.

e. Café Goota memiliki lingkungan yang bersih dan suasana yang nyaman dan menyenangkan.

f. Saran terhadap kualitas secara keseluruhan yang dimiliki Goota.

3. Brand association; sesuatu yang berkaitan dengan ingatan mengenai sebuah produk. Indikator empirik:

a. Mengetahui logo Goota.

b. Logo Goota mewakili jenis makanan yang dijual.

c. Harga makanan Goota sesuai dengan yang didapatkan.

d. Goota memiliki spesialisasi makanan grill.

e. Goota mudah diingat sebagai restoran yang menjual makanan Jepang citarasa Korea.

f. Goota dapat dikategorikan sebagai restoran Jepang yang cocok untuk kaum muda.

g. Dapat menyebutkan apa saja yang ada di dalam benak ketika mendengar nama Goota.

4. Brand loyalty; merupakan ukuran kesetiaan seorang pelanggan pada sebuah merek. Indikator empirik:

a. Berminat untuk mengunjungi Goota lagi karena kemauan sendiri. 
b. Berminat untuk mengunjungi Goota lagi atas ajakan teman atau faktor lainnya.

c. Merekomendasikan Goota kepada orang lain.

d. Responden merasa puas setiap kali berkunjung ke Goota.

e. Goota akan menjadi pilihan utama dalam memilih restoran Jepang.

f. Dapat menyebutkan apa yang menjadi keunggulan utama Goota yang membuat responden tertarik untuk kembali lagi.

\section{B. Brand Strategy}

1. Brand positioning; cara perusahaan untuk menempatkan dirinya dimata target konsumennya dilihat dari keunggulan dan kelebihan yang dimiliki dibandingkan dengan merek-merek pesaing.

Indikator empirik:

a. Goota dapat dikatakan sebagai restoran Jepang yang cocok untuk anak muda.

b. Citarasa Korea dipadu dengan makanan Jepang nampak jelas pada makanan yang ditawarkan Goota.

c. Atmosfer/suasana Goota nyaman untuk berkumpul dan menghabiskan waktu bersama dengan teman.

d. Musik yang dipasang sesuai dengan anak muda.

2. Brand identity; suatu persepsi tentang brand dari suatu perusahaan yang ingin disampaikan kepada konsumen sehingga dapat membentuk persepsi konsumen tentang brand itu sendiri. Indikator empirik:

a. Goota dapat dikatakan sebagai restoran Jepang yang cocok untuk anak muda.

b. Citarasa Korea dipadu dengan makanan Jepang nampak jelas pada makanan yang ditawarkan Goota.

c. Atmosfer/suasana Goota nyaman untuk berkumpul dan menghabiskan waktu bersama dengan teman.

3. Brand personality; cara yang dipakai perusahaan untuk menambah daya tarik dari brand dengan memberi karakteristik pada brand tadi.

Indikator empirik:

a. Penampilan hidangan menarik.

b. Musik yang dipasang sesuai dengan anak muda.

c. Lokasi Goota strategis.

d. Staf berpenampilan rapi dan bersih.

4. Brand communication; cara perusahaan untuk dapat mengkomunikasikan merek (brand) kepada konsumen.
Indikator empirik:

a. Darimana responden mengetahui tentang Goota.

b. Penyajian makanan tepat sesuai dengan yang dipesan.

c. Staf dapat memberikan penjelasan tentang menu dengan baik dan jelas.

d. Goota dapat dengan baik mengenalkan brandnya kepada konsumen.

e. Promosi yang dipakai Goota menarik bagi konsumen.

\section{Teknik Analisa Data}

Untuk data kualitatif dari hasil interview dan observasi, digunakan analisa deskriptif, evaluatif dan konklusif. Sedangkan data kuantitatif dari kuisioner dianalisa dengan menggunakan modus, distribusi frekuensi (fi), mean, dan SEM (Structural Equation Model). SEM digunakan untuk mengetahui bagaimana dan seberapa besar hubungan kausal antara brand equity dan brand strategy.

\section{ANALISA DAN PEMBAHASAN}

\section{Analisa Hasil Wawancara dan Observasi}

Goota didirikan dengan target market utama anak muda dengan range usia 15-30 tahun. Menurut manager Goota, target market Goota selama ini dapat dikatakan sudah sesuai dengan yang diharapkan mengingat konsumen yang datang mayoritas anak muda menengah ke atas juga eksekutif muda, namun ada juga family yang datang berkunjung ke Goota. Konsep dasar dari Goota adalah restoran Jepang untuk anak muda dengan spesialisasi makanan grill seperti sate yang disesuaikan dengan ciri khas anak muda yang cenderung menginginkan sesuatu yang simple dan praktis. Spesialisasi lain yang dimiliki adalah makanan Jepang dengan citarasa Korea sebagai keunikan yang membedakan dari restoran lainnya. Spesialisasi ini tercermin dari nama yang dipilihnya yaitu Japanese charcoal grill and café. Selain itu Goota juga memiliki produk baru yang cukup sukses di pasaran yaitu ice cream gelato yang memiliki spesialisasi di rasa dan kandungan kalori yang rendah. Goota juga menawarkan makanan seperti makanan khas Korea yang terkenal seperti bulgogi, bibimbab, dan sup kimchi. Banyaknya makanan yang ditawarkan Goota sesuai dengan arti dari nama Goota itu sendiri yang berarti lauknya banyak. Nama Goota dipilih oleh owner dengan alasan mudah untuk diingat, mudah dilafalkan serta kata "Goota” memperkuat karakter sebagai restoran Jepang juga terdengar sangat modern sesuai target market Goota. 
Goota memakai logo anak ayam sebagai simbol bahan dasar makanan yang digunakan mayoritas adalah ayam. Bentuk tulisan yang dipakai Goota digunakan untuk mewakili desain interior. Goota mengambil 3 warna sebagai dominasi cafénya yaitu kuning, hijau, dan hitam. Warna kuning dapat dilihat dari logo gambar anak ayam. Warna hijau dan kuning juga dapat dilihat dari seragam para staf Goota. Goota adalah restoran dengan jenis café yang disesuaikan dengan konsepnya yang berupa tempat untuk hang out anak muda, maka Goota memberikan perhatian khusus terhadap interior dan dekorasi ruang. Interior yang digunakan Goota didominasi warna gelap seperti hitam, abu-abu, dan coklat. Hal ini disesuaikan dengan keidentikan anak muda dengan warna gelap. Selain itu musik yang disajikan juga cenderung kearah musik anak muda yang sedang in seperti hip hop.

Promosi Goota dimulai jauh-jauh hari sebelum Goota dibuka yaitu lewat iklan bersambung yang dipasang di Bentoya restaurant sebagai satu manajemen restoran. Selain itu Goota juga bekerja sama dengan bank HSBC, memasang iklan di majalah food and resto dan majalah ice, memasang banner didepan restoran, menyebar brosur di kawasan PTCSupermal Pakuwon Indah, dan juga iklan melalui radio Hard Rock FM mengingat pendengar radio ini yang mayoritas anak muda. Goota juga memberikan soft opening diskon pada para konsumennya. Untuk dapat menarik pengunjung, Goota menawarkan set menu lunch setiap hari Senin-Jumat dari pukul 11.0015.00. Walaupun banyak promosi yang dilakukan Goota, Goota tetap beranggapan bahwa promosi yang terbaik adalah melalui word of mouth dari para konsumennya.

Goota memiliki rencana jangka pendek dan jangka panjang. Untuk rencana jangka pendek, Goota berencana untuk dapat lebih dikenal oleh konsumen serta dapat mencapai target market yaitu anak muda serta tidak menutup kemungkinan untuk target market family juga. Sedang untuk jangka panjangnya, Goota berharap agar dapat menjadi restoran Jepang no 1 di kalangan anak muda atau jika memungkinkan Goota kelak dapat memperluas brandnya.

\section{Analisa Hasil Kuisioner}

1. Brand Awareness, terdiri dari 4 tingkatan, yaitu:

a. Unaware of brand (tidak menyadari merek). Pada tingkatan ini tidak dilakukan pengukuran dikarenakan responden adalah konsumen Goota sendiri yang dapat dipastikan mengenali Goota Japanese charcoal grill and café.

$b$. Brand recognition (pengenalan merek) yaitu merupakan pengurutan merek-merek restoran
Jepang yang ada di PTC dengan pilihan bantuan merek. Penulis menilai jawaban responden yang ada pada pilihan pertama (recognition 1) dimana merek yang menduduki posisi 1 hingga 3 dapat dikatakan bahwa merek tersebut cukup diketahui responden.

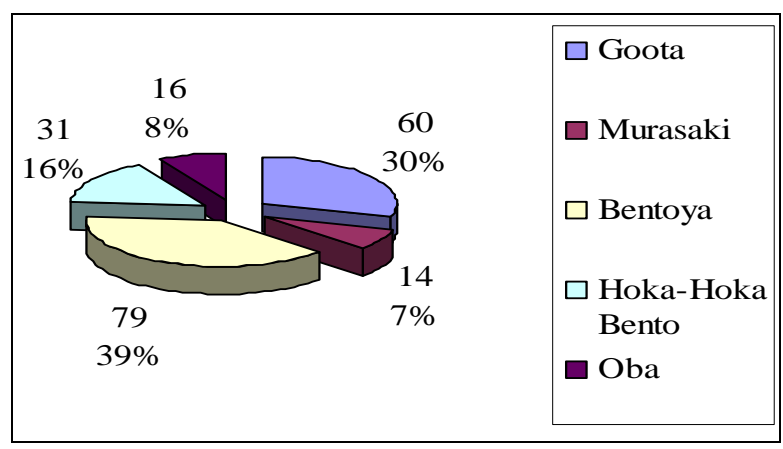

Sumber: data primer, diolah

\section{Gambar 3. Brand Recognition 1 Goota}

Dari gambar 3 dapat diketahui bahwa dari 200 responden memilih 3 merek tertinggi sebagai pilihan di brand recognition 1 adalah Bentoya sebesar 79 orang (39\%), Goota sebesar 60 orang (30\%), dan Hoka-Hoka Bento sebesar 31 orang (16\%). Goota menduduki peringkat kedua dalam brand recognition 1 yang artinya responden cukup mengetahui Goota apabila diberikan pilihan bantuan.

c. Brand Recall (pengingatan kembali terhadap merek) yaitu merupakan 3 merek restoran Jepang yang ada di PTC-Supermal Pakuwon Indah yang paling diingat oleh responden tanpa bantuan. Penulis menilai dari brand recall 1 yaitu pengingatan merek yang disebut responden pertama kali tanpa bantuan.

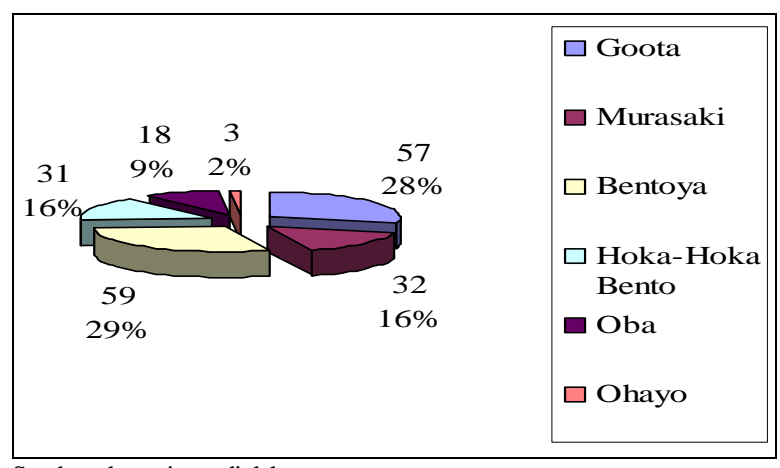

\section{Gambar 4. Brand Recall 1 Goota}

Dari gambar 4 dapat diketahui bahwa dari 200 responden, pilihan untuk brand recall 1 yaitu 
yang disebutkan pertama kali oleh responden adalah Bentoya sebesar 59 orang (29\%), Goota sebesar 57 orang (28\%), dan Murasaki sebesar 32 orang (16\%). Goota berada di urutan kedua dalam brand recall 1 yang berarti bahwa responden cukup mengenal Goota untuk disebutkan pertama kali tanpa diberikan pilihan bantuan.

d. Top of Mind (puncak pikiran) yaitu merupakan tingkatan merek yang paling tinggi yang ada di ingatan responden saat diminta untuk menyebutkan 1 nama merek restoran Jepang yang ada di PTC-Supermal Pakuwon Indah.

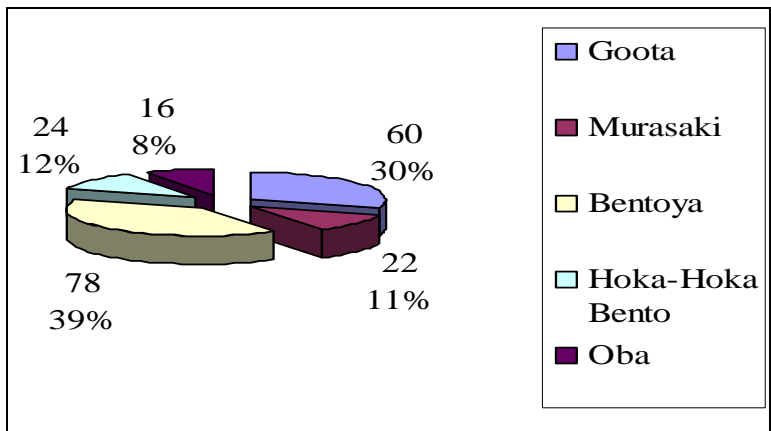

Sumber: data primer, diolah

\section{Gambar 5. Top of Mind Goota}

Dari gambar 5 dapat diketahui bahwa dari 200 responden, pilihan responden untuk top of mind terhadap restoran Jepang yang ada di PTC adalah Bentoya sebesar 78 orang (39\%), Goota sebesar 60 orang (30\%), dan Hoka-Hoka Bento sebesar 24 orang (12\%). Goota menduduki peringkat kedua dalam top of mind yang berarti bahwa cukup banyak responden yang dapat mengingat merek Goota apabila responden ditanya 1 merek restoran Jepang yang ada di PTC-Supermal Pakuwon Indah.

\section{Perceived Quality}

\section{Tabel 1. Perceived Quality Goota}

\begin{tabular}{|c|c|c|c|}
\hline No. & Pernyataan & Mean & $\begin{array}{c}\text { Standard } \\
\text { Deviasi }\end{array}$ \\
\hline 4. & $\begin{array}{l}\text { Goota memberikan pilihan produk yang } \\
\text { menarik, berkualitas dan bervariasi }\end{array}$ & 3.78 & 0.676 \\
\hline 5. & $\begin{array}{l}\text { Staf Goota menyajikan makanan dengan } \\
\text { cepat ( } \pm 15 \text { menit) }\end{array}$ & 3.64 & 0.886 \\
\hline 6. & $\begin{array}{l}\text { Staf Goota berpenampilan rapi dan } \\
\text { bersih }\end{array}$ & 3.74 & 0.652 \\
\hline 7. & $\begin{array}{l}\text { Staf Goota memberikan kualitas } \\
\text { pelayanan dan service yang memuaskan }\end{array}$ & 3.73 & 0.813 \\
\hline \multirow[t]{2}{*}{8.} & $\begin{array}{l}\text { Staf Goota memberikan kualitas } \\
\text { pelayanan dan service yang memuaskan }\end{array}$ & 3.81 & 0.876 \\
\hline & Total Mean & 3.74 & \\
\hline
\end{tabular}

Sumber: data primer, diolah
Berdasarkan tabel 1, didapatkan total mean perceived quality secara keseluruhan sebesar 3,74 yang berarti setuju. Perceived quality Goota di mata konsumen mempunyai tingkatan yang tinggi yang terlihat dari rata-rata jawaban yang diberikan adalah setuju untuk setiap indikatornya yang juga dipertegas dari saran responden yang mengatakan kualitas secara keseluruhan dari Goota adalah bagus.

\section{Brand Association}

\section{Tabel 2. Brand Association Goota}

\begin{tabular}{|c|c|c|c|}
\hline No. & Pernyataan & Mean & $\begin{array}{c}\text { Standard } \\
\text { Deviasi }\end{array}$ \\
\hline & $\begin{array}{l}\text { Logo Goota mewakili jenis } \\
\text { makanan yang dijual }\end{array}$ & 3.06 & 0.919 \\
\hline 11. & $\begin{array}{l}\text { Harga makanan Goota sesuai } \\
\text { dengan yang didapatkan }\end{array}$ & 3.37 & 0.804 \\
\hline 12. & $\begin{array}{l}\text { Goota memiliki spesialisasi } \\
\text { makanan grill (sate) }\end{array}$ & 3.83 & 0.681 \\
\hline 13. & $\begin{array}{l}\text { Goota mudah diingat sebagai } \\
\text { restoran yang menjual makanan } \\
\text { Jepang dengan citarasa Korea }\end{array}$ & 3.53 & 0.856 \\
\hline 14. & $\begin{array}{l}\text { Goota dapat dikategorikan sebagai } \\
\text { restoran Jepang yang cocok untuk } \\
\text { kaum muda }\end{array}$ & 3.93 & 0.665 \\
\hline & Total Mean & 3.54 & \\
\hline
\end{tabular}

Berdasarkan tabel 2, didapatkan total mean brand association secara keseluruhan sebesar 3,54 yang berarti setuju. Brand association responden terhadap Goota dapat disimpulkan tinggi. Hal ini dikarenakan jawaban yang diberikan responden terhadap keunikan-keunikan Goota yang mampu diingat responden adalah positif sekalipun beberapa responden belum mampu mengidentikkan Goota dengan spesialisasi yang ingin disampaikan seperti sebagai restoran Jepang dengan citarasa Korea. Penulis beranggapan hal ini disebabkan brand Goota itu sendiri yang masih baru sehingga responden belum dapat benar-benar memiliki ingatan kuat akan brand Goota itu sendiri. Meskipun demikian tanggapan responden terhadap spesialisasi yang ingin disampaikan Goota sebagai restoran yang menjual makanan grill dan restoran untuk anak muda sudah dapat diterima dengan sangat baik.

4. Brand Loyalty

Dari tabel 3, didapatkan total mean brand loyalty secara keseluruhan sebesar 3,49 yang berarti setuju. Brand loyalty responden Goota dapat dikatakan tinggi. Hal ini dapat dilihat dari rata-rata indikator dalam brand loyalty yang mayoritas dijawab setuju oleh responden. Namun hal ini 
tetap tidak menjamin konsumen untuk mau memilih Goota sebagai pilihan utama dalam memilih restoran Jepang yang ada di PTCSupermal Pakuwon Indah karena mayoritas responden menjawab netral untuk pertanyaan akankah Goota menjadi pilihan utama konsumen dalam restoran Jepang yang ada di PTC-Supermal Pakuwon Indah

\section{Tabel 3. Brand Loyalty Goota}

\begin{tabular}{|c|c|c|c|}
\hline No. & Pernyataan & Mean & $\begin{array}{c}\text { Standard } \\
\text { Deviasi }\end{array}$ \\
\hline 15. & $\begin{array}{l}\text { Saya berminat untuk mengunjungi } \\
\text { Goota lagi karena kemauan sendiri }\end{array}$ & 3.56 & 0.819 \\
\hline 16. & $\begin{array}{l}\text { Saya berminat untuk mengunjungi } \\
\text { Goota lagi atas ajakan teman atau } \\
\text { faktor lainnya }\end{array}$ & 3.79 & 0.818 \\
\hline 17. & $\begin{array}{l}\text { Saya akan merekomendasikan } \\
\text { Goota kepada orang lain }\end{array}$ & 3.54 & 0.769 \\
\hline 18. & $\begin{array}{l}\text { Saya merasa puas setiap kali } \\
\text { berkunjung ke Goota }\end{array}$ & 3.50 & 0.763 \\
\hline 19. & $\begin{array}{l}\text { Goota akan menjadi pilihan utama } \\
\text { saya dalam memilih restoran } \\
\text { Jepang }\end{array}$ & 3.08 & 0.870 \\
\hline & Total Mean & 3.49 & \\
\hline
\end{tabular}

Sumber: data primer, diolah

\section{Brand Positioning}

\section{Tabel 4. Brand Positioning Goota}

\begin{tabular}{llcc}
\hline No. & \multicolumn{1}{c}{ Pernyataan } & Mean & $\begin{array}{c}\text { Standard } \\
\text { Deviasi }\end{array}$ \\
\hline 20. $\begin{array}{l}\text { Goota dapat dikatakan sebagai } \\
\text { restoran Jepang yang cocok untuk } \\
\text { anak muda }\end{array}$ & 3.82 & 0.599 \\
21. $\begin{array}{l}\text { Citarasa Korea dipadu dengan } \\
\text { makanan Jepang nampak jelas pada } \\
\text { makanan yang ditawarkan Goota }\end{array}$ & 3.43 & 0.841 \\
23. $\begin{array}{l}\text { Atmosfer/suasana Goota nyaman } \\
\text { untuk berkumpul dan menghabiskan }\end{array}$ & 3.77 & 0.831 \\
$\begin{array}{l}\text { waktu bersama dengan teman } \\
\text { Musik yang dipasang sesuai dengan } \\
\text { anak muda }\end{array}$ & 3.74 & 0.772 \\
\hline \multicolumn{2}{l}{ Total Mean } & 3.69 & \\
\hline
\end{tabular}

Sumber: data primer, diolah

Tabel 4 menjelaskan bahwa total mean brand positioning secara keseluruhan sebesar 3,69 yang berarti setuju. Strategi brand positioning yang diterima konsumen Goota dapat dikatakan tinggi atau dengan kata lain konsumen sudah dapat menerima Goota sebagai restoran Jepang dengan citarasa Korea jika dilihat dari penyajian makanannya serta target market anak muda dimana untuk dapat memposisikan dirinya Goota mengatur atmosfer/suasana dan musik sedemikian rupa sehingga dapat membedakannya dengan merek lainnya.

\section{Brand Identity}

\section{Tabel 5. Brand Identity Goota}

\begin{tabular}{|c|c|c|c|}
\hline No. & Pernyataan & Mean & $\begin{array}{c}\text { Standard } \\
\text { Deviasi }\end{array}$ \\
\hline & $\begin{array}{l}\text { Goota dapat dikatakan sebagai } \\
\text { restoran Jepang yang cocok untuk } \\
\text { anak muda }\end{array}$ & 3.82 & 0.599 \\
\hline 21. & $\begin{array}{l}\text { Citarasa Korea dipadu dengan } \\
\text { makanan Jepang nampak jelas pada } \\
\text { makanan yang ditawarkan Goota }\end{array}$ & 3.43 & 0.841 \\
\hline 23. & $\begin{array}{l}\text { Atmosfer/suasana Goota nyaman } \\
\text { untuk berkumpul dan } \\
\text { menghabiskan waktu bersama } \\
\text { dengan teman }\end{array}$ & 3.77 & 0.831 \\
\hline & Total Mean & 3.67 & \\
\hline
\end{tabular}

Dari tabel 5 didapatkan total mean brand identity secara keseluruhan yaitu 3,67 yang berarti setuju. Strategi brand identity yang diterima konsumen Goota dapat dikatakan tinggi atau dengan kata lain Goota mampu mempersepsikan brandnya sesuai dengan apa yang ingin disampaikannya kepada konsumen dan konsumen mampu dengan baik menangkap persepsi yang disampaikan Goota.

\section{Brand Personality}

\section{Tabel 6. Brand Personality Goota}

\begin{tabular}{|c|c|c|c|}
\hline No. & Pernyataan & Mean & $\begin{array}{c}\text { Standard } \\
\text { Deviasi }\end{array}$ \\
\hline 22. & Penampilan hidangan menarik & 3.74 & 0.810 \\
\hline 24. & $\begin{array}{l}\text { Musik yang dipasang sesuai } \\
\text { dengan anak muda }\end{array}$ & 3.74 & 0.772 \\
\hline 25. & Lokasi Goota strategis & 3.22 & 0.936 \\
\hline 26. & Staf berpenampilan rapi dan bersih & 3.71 & 0.707 \\
\hline & Total Mean & 3.60 & \\
\hline
\end{tabular}

Berdasarkan tabel 6, didapatkan total mean brand personality secara keseluruhan sebesar 3,60 yang berarti setuju. Strategi brand personality Goota yang diterima konsumen dapat dikatakan tinggi. Dengan kata lain, daya tarik Goota untuk memperkuat karakteristiknya dapat memperjelas brand Goota itu sendiri dilihat dari penampilan hidangan, musik, lokasi, serta staf Goota. Tampaknya usaha Goota melalui strategi yang satu ini masih harus melalui waktu yang panjang serta usaha-usaha lainnya untuk lebih menegaskan karakter yang ingin Goota bentuk.

\section{Brand Communication}

Pada gambar 6 dapat disimpulkan bahwa dari 200 responden menyatakan bahwa responden menge- 
tahui Goota dari tahu sendiri yaitu sebesar 99 orang (49\%). Dari hasil ini dapat diketahui bahwa penyampaian Goota untuk mengenalkan brandnya sangat tidak efektif seperti halnya penyebaran brosur, tidak satupun responden mengetahui adanya brosur yang disebarkan beberapa bulan sebelum Goota dibuka.

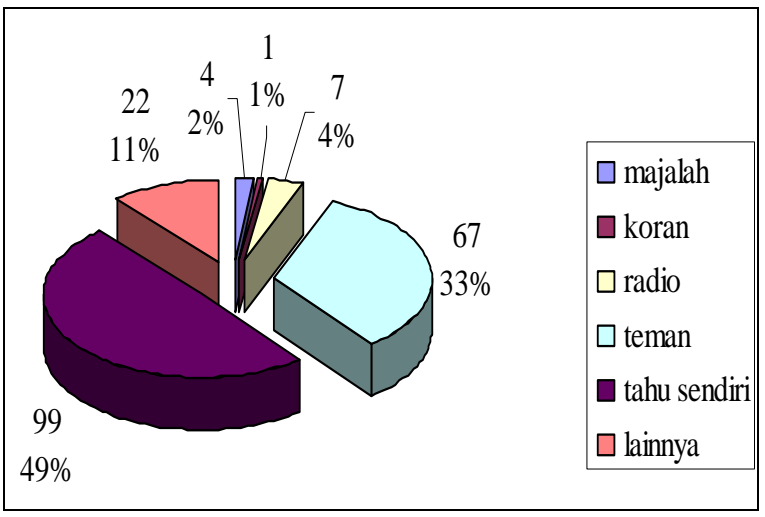

Sumber: data primer, diolah

Gambar 6. Sumber Responden Mengetahui Goota
Tabel 7. Brand Communication Goota

\begin{tabular}{|c|c|c|c|}
\hline No. & Pernyataan & Mean & $\begin{array}{l}\text { Standard } \\
\text { Deviasi }\end{array}$ \\
\hline & $\begin{array}{l}\text { Penyajian makanan tepat sesuai } \\
\text { dengan yang Anda pesan }\end{array}$ & 3.78 & 0.705 \\
\hline 29. & $\begin{array}{l}\text { Staf dapat memberikan } \\
\text { penjelasan tentang menu dengan } \\
\text { baik dan jelas }\end{array}$ & 3.73 & 0.896 \\
\hline 30. & $\begin{array}{l}\text { Goota dapat dengan baik } \\
\text { mengenalkan brandnya kepada } \\
\text { konsumen }\end{array}$ & 3.17 & 0.825 \\
\hline 31. & $\begin{array}{l}\text { Promosi yang dipakai Goota } \\
\text { menarik bagi konsumen }\end{array}$ & 2.78 & 0.865 \\
\hline & Total Mean & 3.37 & \\
\hline
\end{tabular}

Berdasarkan hasil pada tabel 7, didapatkan total mean brand communication secara keseluruhan sebesar 3,37 yang berarti netral. Strategi brand communication yang dilakukan Goota untuk memperkenalkan brandnya dapat dikatakan cukup. Dengan kata lain promosi keluar (usaha memperkenalkan Goota kepada konsumen baru) yang digunakan Goota kurang efektif sedang promosi yang ada di dalam (melalui service yang diberikan para staf) dapat dikatakan baik.

\section{Hubungan Kausal antara Brand Strategy dan Brand Equity}

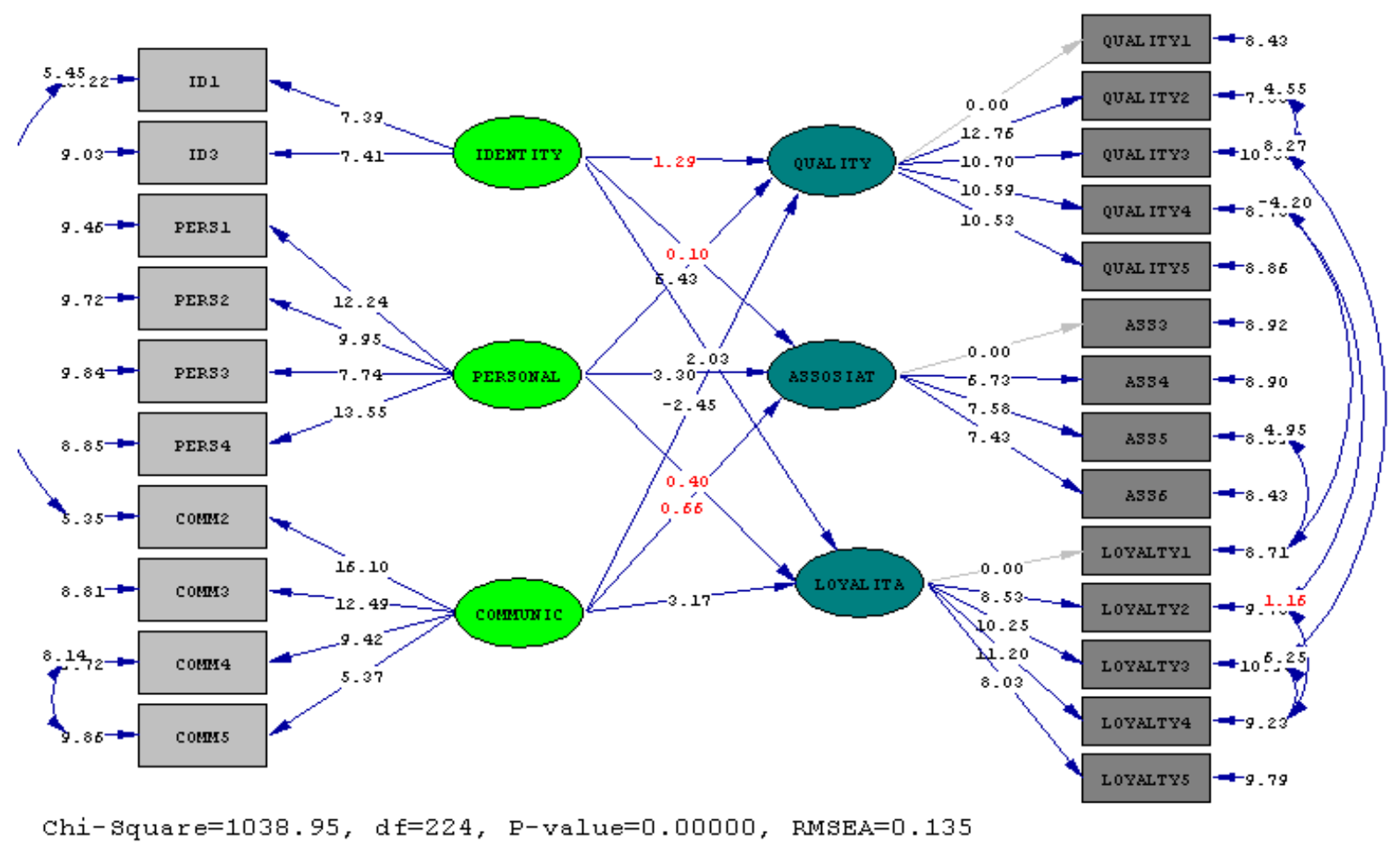

Sumber: data primer, diolah

\section{Gambar 7. Hubungan Kausal antara Brand Strategy dan Brand Equity Goota}


Berdasarkan gambar 7 dapat disimpulkan bahwa:

1. Brand identity mempunyai hubungan kausal yang positif tidak signifikan dengan perceived quality (sebesar 1,29) yang berarti hubungan tersebut berjalan searah dan berhubungan kausal tidak terlalu kuat. Apabila konsumen memiliki persepsi yang benar dan tinggi tentang Goota maka kualitas Goota di mata konsumen juga tinggi dan keduanya berhubungan tidak terlalu kuat. Seperti jika Goota ingin mempersepsikan dirinya sebagai restoran Jepang yang menyajikan makanan dengan cepat maka Goota dapat meningkatkan kualitasnya untuk menyajikan makanan dengan cepat.

2. Brand identity mempunyai hubungan kausal yang positif tidak signifikan dengan brand association (sebesar 0,10) yang berarti hubungan tersebut berjalan searah dan berhubungan kausal tidak terlalu kuat. Apabila konsumen memiliki persepsi yang benar dan tinggi tentang Goota maka ingatan akan Goota di mata konsumen juga tinggi dan keduanya berhubungan tidak terlalu kuat.

3. Brand identity mempunyai hubungan kausal yang positif signifikan dengan brand loyalty (sebesar 2,03) yang berarti hubungan tersebut berjalan searah dan berhubungan kausal kuat. Apabila konsumen memiliki persepsi yang benar dan tinggi tentang Goota maka loyalitas konsumen terhadap Goota juga tinggi dan keduanya berhubungan kuat.

4. Brand personality mempunyai hubungan kausal yang positif signifikan dengan perceived quality (sebesar 6,43) yang berarti hubungan tersebut berjalan searah dan berhubungan kausal kuat. Apabila konsumen mampu mengkarakteristikkan merek Goota dengan sesuatu tinggi maka kualitas Goota di mata konsumen juga tinggi dan keduanya berhubungan kuat.

5. Brand personality mempunyai hubungan kausal yang positif signifikan dengan brand association (sebesar 3,30) yang berarti hubungan tersebut berjalan searah dan berhubungan kausal kuat. Apabila konsumen mampu mengkarakteristikkan merek Goota dengan sesuatu tinggi maka ingatan akan Goota di mata konsumen juga tinggi dan keduanya berhubungan kuat.

6. Brand personality mempunyai hubungan kausal yang positif tidak signifikan dengan brand loyalty (sebesar 0,40) yang berarti hubungan tersebut berjalan searah dan berhubungan kausal tidak terlalu kuat. Apabila konsumen mampu mengkarakteristikkan merek Goota dengan sesuatu tinggi maka loyalitas konsumen terhadap
Goota juga tinggi dan keduanya berhubungan tidak terlalu kuat.

7. Brand communication mempunyai hubungan kausal yang negatif signifikan dengan perceived quality (sebesar -2,45) yang berarti hubungan tersebut berbanding terbalik dan berhubungan kausal kuat. Apabila kemampuan konsumen menangkap komunikasi yang dilakukan Goota tinggi maka kualitas Goota di mata konsumen akan berbanding terbalik dan keduanya berhubungan kuat. Dengan kata lain sekalipun komunikasi yang dilakukan Goota keluarnya kurang baik, namun Goota mampu memberikan kualitas yang baik kedalamnya.

8. Brand communication mempunyai hubungan kausal yang positif tidak signifikan dengan brand association (sebesar 0,66) yang berarti hubungan tersebut berjalan searah dan berhubungan kausal tidak terlalu kuat. Apabila kemampuan konsumen menangkap komunikasi yang dilakukan Goota tinggi maka ingatan akan Goota di mata konsumen juga tinggi dan keduanya berhubungan tidak terlalu kuat.

9. Brand communication mempunyai hubungan kausal yang positif signifikan dengan brand loyalty (sebesar 3,17) yang berarti hubungan tersebut berjalan searah dan berhubungan kausal kuat. Apabila kemampuan konsumen menangkap komunikasi yang dilakukan Goota tinggi maka loyalitas konsumen terhadap Goota juga tinggi dan keduanya berhubungan kuat.

\section{KESIMPULAN DAN SARAN}

\section{Kesimpulan}

1. Brand strategy yang digunakan Goota Japanese charcoal grill and café antara lain brand positioning, brand identity, brand personality, dan brand communication. Goota memperkenalkan diri sebagai restoran Jepang untuk anak muda yang menyajikan makanan Jepang dengan citarasa Korea melalui brand positioning dan brand identity. Selain itu Goota juga menambah daya tariknya melalui musik, staf, dan penampilan hidangan makanannya melalui brand personality. Promosi dan hal lainnya untuk memperkenalkan Goota dilakukan melalui brand communication.

2. Tanggapan konsumen terhadap brand strategy yang dilakukan Goota antara lain:

a. Brand positioning, responden sudah dapat menerima positioning yang ingin dibentuk Goota yang terbukti dari total mean sebesar 3,69 . 
b. Brand identity, responden sudah dapat menerima identity yang ingin dibentuk Goota yang terbukti dari total mean sebesar 3,67.

c. Brand personality, responden sudah dapat menerima personality yang ingin dibentuk Goota yang terbukti dari total mean sebesar 3,60.

d. Brand communication, responden bisa menerima komunikasi yang dilakukan Goota namun tidak terlalu berpengaruh pada keputusan responden dikarenakan sebagian besar promosi yang dilakukan kurang efektif yang terbukti dari total mean sebesar 3,37. Untuk promosi keluar (usaha memperkenalkan Goota kepada konsumen baru) yang digunakan Goota kurang efektif sedang promosi yang ada di dalam (melalui service yang diberikan para staf) dapat dikatakan baik.

3. Brand equity yang diterima konsumen yang terdiri dari:

a. Brand awareness, responden sudah berada pada tingkatan aware yang dapat dikatakan cukup tinggi terhadap merek. Hal ini dapat dilihat dari hasil kuisioner dimana merek Goota menduduki peringkat kedua untuk brand recognition 1, brand recall 1, dan top of mind.

b. Perceived quality, responden sudah memiliki tingkatan yang tinggi yang terbukti dari total mean sebesar 3,74.

c. Brand association, responden sudah memiliki tingkatan yang tinggi yang terbukti dari total mean sebesar 3,54.

d. Brand loyalty, responden sudah memiliki tingkatan yang tinggi yang terbukti dari total mean sebesar 3,49.

4. Hubungan kausal antara brand strategy yang sudah dilakukan Goota Japanese charcoal grill and café dan brand equity yang sudah diterima konsumen adalah rata-rata mempunyai hubungan kausal yang positif signifikan yang berarti:

a. Cara Goota untuk mempersepsikan mereknya bagus dan baik serta mampu diterima dengan benar oleh konsumen, hal ini akan berbanding sejalan dengan brand equity yang diterima konsumen.

b. Cara Goota untuk mengkarakteristikkan mereknya dengan sesuatu telah dapat diterima dengan baik oleh konsumen yang juga berbanding sejalan dengan brand equity yang diterima oleh konsumen.

c. Cara Goota untuk mengkomunikasikan mereknya kepada konsumen dapat dikatakan netral. Namun demikian, komunikasi yang dilakukan
Goota terhadap kualitas yang diterima konsumen berbanding terbalik. Hal ini dikarenakan Goota tetap menjaga kualitasnya sekalipun komunikasi yang dilakukan kurang dapat menjangkau konsumen. Tetapi terhadap ingatan dan loyalitas konsumen terhadap Goota, komunikasi ini berbanding sejalan.

5. Brand strategy yang sudah dilakukan Goota dengan tujuannya masing-masing rata-rata sudah tersampaikan dan diterima dengan benar oleh konsumen Goota sehingga hal ini menyebabkan per tingkatan brand equity yang sudah diterima oleh konsumen Goota dapat dikatakan tinggi.

\section{Saran}

1. Goota Japanese charcoal grill and café sebaiknya meningkatkan brand communication yang digunakan khususnya promosi yang dapat dilakukan dengan:

a. Untuk majalah, Goota sebaiknya bekerja sama dengan majalah-majalah yang lebih populer dan bersifat komersil namun tetap sesuai dengan target marketnya seperti majalah Cosmopolitan, Cosmogirl, dan lainnya serta memasang iklan secara periodik dengan jangka waktu 2 minggu perbulannya.

b. Untuk koran, Goota sebaiknya melakukan pemasangan iklan di koran-koran yang populer dikalangan masyarakat seperti Jawa Pos, Surabaya Pos, dan lainnya dengan jangka waktu 4 kali selama 1 bulan.

c. Untuk radio, promosi yang dilakukan sebaiknya lebih dari 1 stasiun radio (EBS FM, DJ FM, JJ FM, dan lainnya) dengan tetap mempertimbangkan target pendengar juga sebaiknya dilakukan secara periodik dengan jangka waktu 2 minggu perbulannya.

d. Untuk brosur, lingkup penyebarannya diperluas tidak hanya di PTC-Supermal Pakuwon Indah seperti menyebar di kampus-kampus, sekolah-sekolah, dan lainnya.

2. Goota Japanese charcoal grill and café sebaiknya menambah variasi produk yang ditawarkan, misalnya meningkatkan ciri khas fusion pada makanan Jepang dan Korea. Selain itu dengan membuat menu fusion baru dan penawaran khusus atas menu fusion baru tersebut seperti harga khusus ataupun diskon untuk menu fusion baru sehingga secara tidak langsung Goota dapat sekaligus mempromosikan brandnya.

3. Melihat brand strategy yang dilakukan Goota ratarata dapat diterima oleh konsumen, maka akan lebih baik apabila Goota Japanese charcoal grill 
and café lebih mengembangkan brand strategy yang digunakannya sehingga dapat tercipta brand equity yang sangat kuat di setiap tingkatannya yang dapat dilakukan dengan meningkatkan kualitas pelayanan yang diberikan, membuka cabang baru, menonjolkan karakteristik dari makanan Jepang yang dipadukan dengan citarasa Korea, dan lainnya.

\section{DAFTAR PUSTAKA}

Boone, L.E., \& Kurtz, D.L. (2005). Contemporary marketing 2005. USA: Thomson SouthWestern.

Brand (2006, Juni 7). Wikipedia: The free encyclopedia. September 19, 2006. http://en.wikipedia. org/wiki/Rebranding

Bungin, B. (2004). Metodologi penelitian kualitatif. Jakarta: PT Raja Grafindo Persada.

Burns, A.C., \& Bush, R.F. (2003). Marketing rese$\operatorname{arch}\left(4^{\text {th }}\right.$ ed). New Jersey: Prentice Hall.

Cooper, D.R., \& Schindler, P.S. (2001). Business research methods $\left(6^{\text {th }}\right.$ ed). Singapore:McGrawHill.

------(2006). Marketing research. Boston: McGrawHill.

Crainer, S., \& Dearlove, D. (2003). The ultimate book of business brands: Insights from the world's 50 greatest brands. United Kingdom: Capstone.

Departemen Pendidikan Nasional. (2001). Kamus besar bahasa Indonesia. Jakarta: Balai Pustaka.

East, R. (1997). Consumer behaviour. London: Prentice Hall.

Gelder, S.V. (2005). Global brand strategy. London: Kogan Page.

Hair, J.F., Rolph, E.A., Ronald, L.T. \& William, C.B. (1998). Multivariate data analysis (5 $5^{\text {th }}$ ed). Upper Saddle River: Prentice Hall.

------, Bush, R.P., \& Ortinau, D.J. (2004). Marketing research ( $2^{\text {nd }}$ ed). Boston: McGraw-Hill.

Hassanien, A., \& Baum, T. (2002). Hotel repositioning through property renovation. Journal of tourism and hospitality research" vol.4, no.2, pp. 144-157. UK: Henry Stewart Publication, 1467-3584.

Kartajaya, H. (2004). On positioning. Bandung: Mizan Media Utama.
Keller, K.L. (1993). Conceptualizing, measuring, and managing customer based brand equity $\left(2^{\text {nd }}\right.$ ed). New Jersey: Prentice Hall.

Kotler, P. (1987). Dasar-dasar pemasaran. Jakarta: CV. Intermedia.

- (2002). Manajemen pemasaran (edisi 1). Jakarta: Prenhallindo.

(2002). Manajemen pemasaran (edisi 2). Jakarta: Prenhallindo.

Kotler, P., \& Armstrong, G. (2004). Principles of marketing $\left(10^{\text {th }}\right.$ ed). New Jersey: Prentice Hall.

Kuncoro, M. (2003). Metode riset untuk bisnis dan ekonomi. Jakarta: Erlangga.

Moleong, L.J. (2000). Metodologi penelitian kualitatif. Bandung: PT. Remaja Rosdakarya.

Nawawi, H.H., \& Hadari, H.M.M. (1992). Instrumen penelitian bidang sosial. Yogyakarta: Gajah Mada University Press.

Randall, G. (2001). The art of marketing vol. 7 branding. New Delhi: Crest Publishing House.

Rangkuti, F. (2004). The power of brands. Jakarta: PT. Gramedia Pustaka Utama.

Saragih B. et al. (1994). Metode penelitian sosial ekonomi. Bogor: Direktorat Perguruan Tinggi Swasta.

Schultz, D.C., \& Barnes, B.E. (1999). Strategic brand communication campaigns. USA: NTC Business Books.

Schultz, D.E., \& Schultz, H.F. (2004). Brand babble. USA: Thomson South-Western.

Soehadi, A.W. (2005). Effective branding: Konsep dan aplikasi pengembangan merek yang sehat dan kuat. Bandung: Quantum Bisnis \& Manajemen.

Suryabrata, S. (1983). Metodologi penelitian. Jakarta: CV. Rajawali.

Susanto, A.B., \& Wijanarko, H. (2004). Power branding: Membangun merek unggul dan organisasi pendukungnya. Jakarta: Quantum Bisnis \& Manajemen.

Tjiptono, F. (2005). Brand management and strategy. Yogyakarta: Andi.

Umar, H. (2003). Metode riset perilaku konsumen jasa. Jakarta: Ghalia Indonesia. 